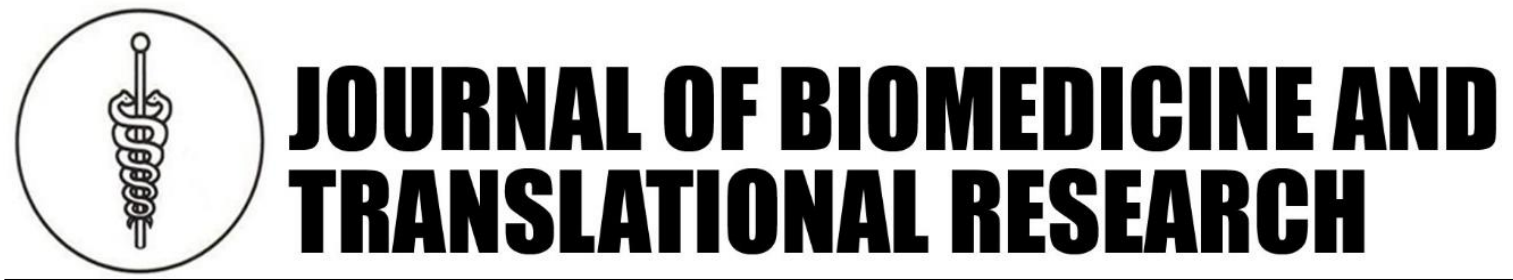

Copyright $@ 2018$ by Faculty of Medicine Diponegoro University and Indonesian Medical Association, Central Java Region

\title{
Malaria, hepatitis B and HIV /AIDS, and their co-infection among Patients Visiting Health Centres in Akure, Nigeria
}

\author{
Afolabi, Olajide J*, Aremo, Oluwabunmi H and Itansanmi, Anuoluwa I
}

Department of Biology, Federal University of Technology Akure, Nigeria

\section{Article Info}

History:

Received: 22 Okt 2018

Accepted: 07 Nov 2018

Available: 31 Dec 2018

\begin{abstract}
Background: Co-infection is the simultaneous infection of host by multiple pathogenic species, which may co-exist together or not

Objective: To investigate the prevalence and co-infection of malaria, hepatitis B and HIV/AIDS using four different locations in Akure, Ondo State.

Methods: Blood samples were aseptically collected from the left thumbs of 500 patients visiting health centres in Akure using sterile lancets. Thin and thick smear of the blood samples were observed for malaria parasites using X100 magnification of the light microscope. Hepatitis B and HIV/AIDS were tested using diagnostic test kits.

Results: The results show that highest prevalence of malaria was observed in ObaIle $(82.09 \%)$ while the lowest was observed in Ala-Ajagbusi (73.17\%). Similarly, highest age prevalence of malaria was observed in age group 11-20 years (90.8\%) while the lowest prevalence was found in age group 21-30 years (70.03\%). Highest prevalence of hepatitis $(7.06 \%)$ was observed in Orita-Obele while the lowest prevalence was observed in Ala- Ajagbusi (4.88\%). HIV/AIDS infection was found Orita-Obele $(1.76 \%, \mathrm{n}=3)$ and Ala-Ajagbusi $(2.44 \%, \mathrm{n}=2)$. The results show that all the individuals that tested positive to hepatitis B virus and HIV also tested positive to malaria. Also, 3 of the 5 individuals infected with HIV/AIDS tested positive to hepatitis B virus. Similarly, malaria, hepatitis B virus and HIV co-exist in 2 individuals; 1 in age group 21-30 years and 1 in age group 31-40 years.

Conclusion: Coinfection of malaria with hepatitis and HIV/AIDS suggests that malaria can co-exist in the same host. This calls for prompt malaria treatment among the immunocompromised patients. More so, there should be adequate and consistent public health advocacy programs, to enlighten the population about malaria, hepatitis B and HIV/AIDS in order to completely mitigate the disease spread in the area.
\end{abstract}

Keywords: Prevalence; Co-infection; Malaria; Hepatitis B; HIV/AIDS.

Permalink/ DOI: https://doi.org/10.14710/jbtr.v4i2.3457

\section{INTRODUCTION}

Co-infection is the simultaneous infection of a host by multiple pathogenic species; which may co-exist together or not. Most co-infections are transmitted through body fluids (saliva, blood, sweat etc). Malaria is a mosquito-borne infectious disease caused by protozoan parasites of blood-Plasmodium species; affecting humans and other animals.

\footnotetext{
* Corresponding author:

E-mail: ojafolabi@futa.edu.ng
}

The disease is most commonly transmitted by an infected female Anopheles mosquito. The mosquito bite introduces the parasites from the mosquito's saliva into a person's blood. The parasites travel to the liver where they mature and reproduce. Malaria causes symptoms that typically include fever, tiredness, vomiting, and headaches ${ }^{1}$. In severe cases it can cause yellow skin, seizures, coma or death. Symptoms usually begin ten to fifteen days after being bitten. If not properly treated, people may have recurrences of the disease months later ${ }^{2}$. Prevalence of malaria in 
Akure has previously been reported in the study area to be $45.79 \%^{3}$. The risk of malaria can be reduced by preventing mosquito bites through the use of mosquito nets and insect repellents, or with mosquito control measures such as spraying insecticides and habitat evacuation ${ }^{4}$. Hepatitis B is an infectious disease caused by the hepatitis B virus (HBV) that affects the liver. It can cause both acute and chronic infections ${ }^{5}$. Hepatitis $B$ virus is transmitted through exposure to infectious blood or body fluids. It is 50 to 100 times more infectious than HIV. Possible forms of transmission include sexual contact, blood transfusions and transfusion with other human blood products, re-use of contaminated needles and syringes, and vertical transmission from mother to child (MTCT) during childbirth. Without intervention, a mother who is positive for $\mathrm{HBsAg}$ has a $20 \%$ risk of passing the infection to her progeny at birth ${ }^{6}$. Many people have no symptoms during the initial infection while some develop a rapid onset of sickness with vomiting, yellowish skin, tiredness, dark urine and abdominal pain ${ }^{1}$. Chronic symptoms of infection include cirrhosis and liver cancer ${ }^{5.7}$. Often, these symptoms last a few weeks and rarely does the initial infection result in death. It may take 30 to 180 days for symptoms to begin. In those who get infected around the time of birth $90 \%$ develop chronic hepatitis B while less than $10 \%$ of those infected after the age of five get the vaccine against $\mathrm{HBV}^{\mathbf{1}}$.

The human immunodeficiency virus (HIV) is a lentivirus (a subgroup of retrovirus) that causes HIV infection and over time acquired immunodeficiency syndrome (AIDS). AIDS is a condition in humans in which progressive failure of the immune system allows life-threatening opportunistic infections ${ }^{8}$. Infection with HIV occurs by the transfer of blood, pre-ejaculate semen, vaginal fluids or breast milk. Within these bodily fluids, HIV is present as both free virus particles and virus within infected immune cells ${ }^{9}$. HIV infects vital cells in the human immune system such as helper $\mathrm{T}$ cells (specifically CD4 ${ }^{+} \mathrm{T}$ cells), macrophages, and dendritic cells. HIV infection leads to low levels of $\mathrm{CD}^{+} \mathrm{T}$ cells through a number of mechanisms, including pyroptosis of abortively infected $\mathrm{T}$ cells, apoptosis of uninfected bystander cells, direct viral killing of infected cells, and killing of infected $\mathrm{CD}^{+}{ }^{+} \mathrm{T}$ cells by CD8 cytotoxic lymphocytes that recognize infected cells ${ }^{\mathbf{1 0}}$. When $\mathrm{CD} 4^{+} \mathrm{T}$ cell numbers decline below a critical level, cell-mediated immunity is lost, and the body becomes progressively more susceptible to opportunistic infections like malaria, tuberculosis, hepatitis $\mathrm{B}$ and so on ${ }^{\mathbf{1 1}}$. This research seeks to determine the prevalence of malaria, hepatitis B, HIV/AIDS and their co-infection in Akure metropolis; Ondo State.

\section{MATERIALS AND METHODS}

Prior to the commencement of the research, approvals for the study were obtained from the Department of Disease Control of the Ondo State Ministry of Health. Also, informed consent of the subjects was obtained after focus group discussion in English and native Language, where the participants were made to know the benefits and discomfort of their participation in the study. Four community health centres within Akure metropolis were considered as sample collection centres. These include: Health centres in FUTA where the subjects comprised of students and lecturers, Orita-Obele where the subjects comprised of civil servants, traders and students, AlaAjagbusi which comprised of civil servant and traders, Oba-Ile which comprised of public servants, retirees and traders. Five hundred symptomatic patients who came to the community health centres for medical check-up were randomly selected for the study. Subsequently, blood samples were aseptically collected from the left thumb of the subjects using a sterile lancet. Before collection, the thumb was cleaned with cotton wool dampened with $70 \%$ ethanol to remove dirt and oils from the ball of the finger. Then the thumb was stroked to stimulate blood circulation and gentle pressure was applied on the finger before it was gently punctured by the sterile lancet. Drops of the blood were collected in the EDTA bottles for thin and thick film preparation and blood testing. Respondent fingers were immediately swabbed with cotton wool soaked with $70 \%$ ethanol to prevent entry of pathogens into the wound. Thin and thick smears of the samples were prepared on sterile slides and subsequently stained with Giemsa at $\mathrm{pH}$ 7.2. The slide preparations were observed for Falciparum malaria under X 1000 magnification of the light microscope. The Alere Determine HIV-1/2 Test System (home collection kit) also known as Abbot kit (produced by Abbot

Table 1. Prevalence of Malaria, Hepatitis B and HIV/ AIDS in Akure

\begin{tabular}{lcccc}
\hline Location & Number examined & $\begin{array}{c}\text { Malaria } \\
\mathrm{n}(\%)\end{array}$ & $\begin{array}{c}\text { Hepatitis B } \\
\mathrm{n}(\%)\end{array}$ & $\begin{array}{c}\text { HIV /AIDS } \\
\mathrm{n}(\%)\end{array}$ \\
\hline FUTA & 181 & $140(77.35)$ & $11(6.08)$ & $0(0.00)$ \\
Orita Obele & 170 & $130(76.47)$ & $12(7.06)$ & $3(1.76)$ \\
Ala-Ajagbusi & 82 & $60(73.17)$ & $4(4.88)$ & $2(2.44)$ \\
Oba-Ile & 67 & $55(82.09)$ & $4(5.97)$ & $0(0.00)$ \\
\hline Total & 500 & $385(77.00)$ & $31(6.02)$ & $5(1.00)$ \\
& & & & \\
\hline Gender & 167 & $126(75.45)$ & $11(6.59)$ & $2(1.19)$ \\
Male & 333 & $259(77.78)$ & $20(6.01)$ & $3(0.90)$ \\
Female & 500 & $385(77.00)$ & $31(6.02)$ & $5(1.00)$ \\
\hline Total & \multicolumn{5}{l}{}
\end{tabular}


Diagnostics) was used to diagnose HIV/AIDS infection while the HBsAg rapid test strips were used for Hepatitis B test among the subjects. Data obtained were subjected to Chi-square $\left(\chi^{2}\right)$ and one-way ANOVA (Analysis of Variance) at $p<0.05$ using SPSS 21.0 (Statistical Package for the Social Sciences).

\section{RESULTS}

Total of 500 respondents were sampled during the study which consist of 181, 170, 82 and 67 from FUTA, Orita-Obele, Ala-Ajagbusi and Oba-Ile respectively (Table 1). Different erythrocytic stages (trophozoites, schizonts and merozoites) of Falciparum malaria parasite were observed in 385 subjects were infected with the disease in Orita-Obele and Ala-Ajagbusi with prevalence of $1.76 \%$ and $2.44 \%$ respectively. A total infection rate of $1.0 \%$ was observed in the study area. Of the 5 subjects that were positive for HIV/AIDS infection, $2(1 \cdot 18 \%)$ were male while $3(1 \%)$ were female subjects.

Table 2 shows the distribution of malaria infection among the age groups. The highest prevalence of malaria $(90.8 \%)$ was noted in age-group 11-20 years while the least prevalence $(70 \cdot 03 \%)$ of the disease was observed in age-group 21-30 years.

The prevalence of HIV/AIDS infection was not significantly different between gender $\left(\chi^{2}=0.099\right.$; $\mathrm{p}=0.753, \mathrm{p}>0.05)$. Coinfection of the malaria parasite

Table 2. Distribution of Malaria Infection among Age groups in Akure

\begin{tabular}{cccc}
\hline $\begin{array}{c}\text { Age group } \\
\text { (Years) }\end{array}$ & $\begin{array}{c}\text { Number } \\
\text { Examined }\end{array}$ & $\begin{array}{c}\text { Infected } \\
\text { Individuals (n) }\end{array}$ & $\begin{array}{c}\text { Prevalence } \\
(\boldsymbol{\%})\end{array}$ \\
\hline $1-10$ & 8 & 6 & 75.00 \\
$11-20$ & 87 & 79 & 90.80 \\
$21-30$ & 307 & 215 & 70.03 \\
$31-40$ & 55 & 51 & 82.09 \\
$41-50$ & 25 & 19 & 76.00 \\
51 and above & 18 & 15 & 83.30 \\
\hline Total & 500 & 385 & 77.00 \\
\hline
\end{tabular}

$\chi^{2}=25 \cdot 898 ; p=0.00, p<0 \cdot 05$

respondent blood samples given a total prevalence of $77 \%$. One hundred and forty (140) subjects of the 181 subjects observed in Federal University of Technology Akure (FUTA) were positive to malaria parasite given a prevalence of $77.35 \%, 130$ subjects of the 170 sampled in Orita Obele Estate were infected with malaria parasite while 60 and 55 subjects were positive with prevalence of $73.17 \%$ and $82.09 \%$ in AlaAjagbusi and Oba-Ile Estate respectively (Table 1). The result further shows that of the 167 males examined, 126 of them were infected with malaria parasite given a prevalence of $75.45 \%$. Two hundred and fifty-nine females (259) of the 333 females were also infected with malaria parasite.

The result presented in Table 1 also shows that of the 181 subjects examined for Hepatitis B in FUTA, 11 of them were positive given a prevalence of $6.08 \%$. In Orita-Obele, 12 subjects of the 170 subjects were positive for Hepatitis B given a prevalence of $7.06 \%$. Meanwhile, in Ala-Ajagbusi and Oba-Ile, 4 subjects each were positive for the disease given prevalence of $4.88 \%$ and $5.97 \%$ respectively. Generally, a total of 31 subjects of the 500 subjects were observed to be positive for Hepatitis B virus in the study area, given a total prevalence of $6 \cdot 2 \%$. Among the 500 subjects examined for Hepatitis B, 167 were male, while 333 were female gender. Number of male and female infected with Hepatitis B Virus were 11 and 20 given prevalence of $6.6 \%$ and 6.0 respectively. Chi-Square analysis of the data shows that there is no significant difference in the prevalence between gender $(\mathrm{P}>0 \cdot 05)$.

The HIV/AIDS result as observed in different locations in Akure reveals that no subject in FUTA and Oba-Ile was infected with HIV/AIDS while 2 and 3 and hepatitis B virus was observed in 31 subjects in this study, 12 subjects were observed to harbor both malaria parasite and hepatitis B virus in FUTA, 14 subjects harbor the two parasites in Orita-Obele, 3 subjects harbor the two parasites in Ala-Ajagbusi while 2 subject harbor the two parasites in Oba-Ile (Table 3). Similarly, coinfection of malaria and HIV was noted in 5 subjects; 3 in Orita-Obele and 2 in Ala-Ajagbusi. It was generally observed that all the 5 subjects that were positive for HIV/AIDS also tested positive for malaria. In contrast, of the 5 subjects positive for HIV/AIDS, only 3 of them tested positive for hepatitis B virus; 2 individuals in Orita-Obele and 1 in Ala-Ajagbusi (Table 3).

Coinfection of diseases as presented in Table 4 shows that coinfection was absent in age groups 1-10 and 11-20 years. Meanwhile, coinfection of malaria and hepatitis B virus was observed in 12 subjects in age group 21-30 years, 14 subjects in age group 31-40 years, 3 and 2 subjects in 41-50 years and above 51 years old respectively. One individual each was noted to harbor malaria and HIV; hepatitis and HIV in age group 21-30 years. Also, 3 individuals harbor malaria and HIV in age group 31-40 years, 2 individuals harbor hepatitis B and HIV while the three diseases (malaria, hepatitis B and AIDS) co-exist in 1 individual each in age group 21-30years and 31-40 years. It was generally observed that co-infection of malaria, hepatitis B and HIV infection was found only in age groups 31-40 and 41-50 years (Table 4).

\section{DISCUSSION}

This study reveals that of the 500 subjects examined for malaria, hepatitis $\mathrm{B}$ and HIV/AIDS 
Table 3. Coinfection of Malaria, Hepatitis B and HIV/AIDS in Akure

\begin{tabular}{lccccc}
\hline Location & $\begin{array}{c}\text { Number } \\
\text { Examined }\end{array}$ & $\begin{array}{c}\text { Coinfection of } \\
\text { Malaria \& } \\
\text { Hepatitis }\end{array}$ & $\begin{array}{c}\text { Coinfection of } \\
\text { Malaria \& } \\
\text { HIV }\end{array}$ & $\begin{array}{c}\text { Coinfection of } \\
\text { Hepatitis \& } \\
\text { HIV }\end{array}$ & $\begin{array}{c}\text { Coinfection of } \\
\text { Malaria, Hepatitis \& } \\
\text { HIV }\end{array}$ \\
\hline FUTA & 181 & $8(4.42 \%)$ & $0(0.0 \%)$ & $0(0.0 \%)$ & $0(0.0 \%)$ \\
Orita Obele & 170 & $9(5.29 \%)$ & $3(1.76 \%)$ & $2(1.18 \%)$ & $1(0.59 \%)$ \\
Ala-Ajagbusi & 82 & $2(2.44 \%)$ & $2(2.44 \%)$ & $1(1.23 \%)$ & $1(1.22 \%)$ \\
Oba-Ile & 67 & $1(1.49 \%)$ & $0(0.0 \%)$ & $0(0.0 \%)$ & $0(0.0 \%)$ \\
\hline Total & 500 & $20(4.0 \%)$ & $5(1.0 \%)$ & $3(0.6 \%)$ & $2(0.4 \%)$ \\
\hline
\end{tabular}

Note: Figures in brackets are prevalence of coinfections

infections in the study area, 385 were infected with malaria given a total prevalence of $77 \%, 31$ subjects were infected with hepatitis $\mathrm{B}$ virus given a total of $6.2 \%$ and 5 subjects were positive to HIV test given a total prevalence of $1.0 \%$. It was further observed that the prevalence of the three diseases was not significantly different among the four locations observed in the study. The subjects that were positive to malaria infection were given antimalarial drugs by competent medical personnel in the Health Centers while those that were positive for hepatitis and HIV/AIDS were referred to Virology department in Ondo State Teaching Hospital and HIV/AIDS Centre in Akure for further confirmatory tests, counselling and therapy. The highest prevalence of malaria (77\%) when compared to the other two diseases (hepatitis B and HIV/AIDS) shows that malaria is the most dominant disease in Akure metropolis. This finding is in accordance with the World Health Organization Malaria report ${ }^{12}$ that malaria is the most important public health problem in terms of morbidity and mortality causing more than 200 million morbidity and 655,000 mortality every year. The high prevalence of malaria has been associated with the increase in the population living in malaria endemic regions ${ }^{13}$. distribution of malaria among age groups shows that the prevalence of the disease is higher among 11-20 years and 30-41 years. This shows that the lower age groups are more predisposed to malaria infections than the older age groups. This might be because the lower age groups are still building up immunity against malaria parasites compared to the older age groups where their immunity has been fully developed to combat the malaria parasites.

The results of this study further show that there is no significant difference in prevalence of malaria, hepatitis $\mathrm{B}$ and HIV/AIDS between genders. This implies that gender has nothing to do with the transmission of the diseases. Both gender have equal chance of contracting the diseases when exposed to the parasites. In addition, it was observed that malaria parasite, hepatitis B virus and Human Immunodeficiency Virus can co-habit in immunodeficient or immunocompromised hosts. All the individuals that were positive for hepatitis B and HIV/AIDS tests were also positive for malaria test. This also suggests that individuals with HIV/AIDS have higher risk of contracting hepatitis B virus. It shows that malaria and HIV/AIDS could co-exist in human host. This coinfection characteristic of malaria

Table 4. Coinfection of Malaria, Hepatitis B and HIV/AIDS Infections among Age groups in Akure

\begin{tabular}{cccccc}
\hline $\begin{array}{c}\text { Age group } \\
\text { (years) }\end{array}$ & $\begin{array}{c}\text { Number } \\
\text { Examined }\end{array}$ & $\begin{array}{c}\text { Coinfection of } \\
\text { Malaria \& } \\
\text { Hepatitis }\end{array}$ & $\begin{array}{c}\text { Coinfection of } \\
\text { Malaria \& HIV }\end{array}$ & $\begin{array}{c}\text { Coinfection } \\
\text { of Hepatitis } \\
\text { \& HIV }\end{array}$ & $\begin{array}{c}\text { Coinfection of } \\
\text { Malaria, } \\
\text { Hepatitis } \\
\text { \& HIV }\end{array}$ \\
\hline $1-10$ & 8 & 0 & 0 & 0 & 0 \\
$11-20$ & 87 & 0 & 0 & 0 & 0 \\
$21-30$ & 307 & 3 & 1 & 1 & 1 \\
$31-40$ & 55 & 8 & 3 & 2 & 1 \\
$41-50$ & 25 & 4 & 1 & 0 & 0 \\
51 above & 18 & 3 & 0 & 0 & 0 \\
\hline Total & 500 & 20 & 5 & 3 & 2 \\
\hline
\end{tabular}

Low infection rates of hepatitis B (6.2\%) and HIV/AIDS (1.0\%) might be as a result of increase in the public enlightenment in the area. The people living in endemic areas which include Akure metropolis are aware of the various preventive measures for the two diseases. Low prevalence of hepatitis $B$ recorded in the study area is supported by Denue ${ }^{14}$ at medical wards of University of Maiduguri Teaching Hospital, Nigeria where a low prevalence of $12.3 \%$ for hepatitis B virus was reported among HIV positive patients. The parasite and HIV has also been reported by Orlov et $a l^{15}$. The result of this study also shows that three of the five individuals infected with HIV/AIDS also tested positive for hepatitis B virus. This shows that presence of HIV in a host increases the prevalence of hepatitis B virus in the same host and vice versa. The coinfection of HBV and malaria parasite noted in this research is contrary to the report of Sharif et $a l^{16}$ in Kano. The authors reported that presence of HBV and malaria coinfection reduces the severity of $\mathrm{HBV}$ and malaria as 
mono infection in Kano. The coinfection of HBV and malaria observed in this study suggests that HBV and malaria parasite can co-exist in a host and HBV patients have the higher risk of contracting malaria. This result concurs with the report of Barcus et $a l^{17}$. The authors in their study showed that the presence of $\mathrm{HBV}$ in a host could negatively affect the prognosis of malaria infection. Olatunji et $a l^{18}$ also reported that HBV and malaria co-infection significantly affect the hematological and liver function indices of malaria patients in Ilorin, Nigeria.

\section{CONCLUSIONS}

High prevalence of malaria observed among the 500 symptomatic patients attending health centers in the study area suggests that campaigns about the prevention and control of malaria infection should be intensified. Presence of malaria parasite in all the subjects that are infected with hepatitis and HIV/AIDS suggests that these patients should always be encouraged to employ all preventive measures such as habitat control, use of treated nets and regular medical checkup and prompt treatment of malaria when infected. Low prevalence of HIV/AIDS observed in this research shows high awareness of the disease in the study area. This implies that people employed several preventive measures against the disease. Nevertheless, the HIV/AIDS campaign needs to be intensified to control the disease.

\section{LIMITATIONS OF THE STUDY}

The HBV and HIV tests were done using rapid serology assay (diagnostic kits) instead of using ELISA, PCR or Western Blot Test due to financial constraint. This gap is well noted in the study and will subsequently be filled in a later study with fund support.

\section{ACKNOWLEDGEMENT}

The authors are grateful to the Public Health Coordinators in Orita Obele, Arakale and Oba-Ile for their support in mobilizing the subjects used for this research. We also acknowledged the contribution of Mrs E.T. Alade in preparation of the reagents used for this research.

\section{REFERENCE}

1. World Health Organization (WHO) (2014). Methods for Surveillance of Antimalarial Drug Efficacy. Geneva: World Health Organization, 2014.

2. Caraballo, H. (2014). "Emergency Department Management of Mosquito-borne Illness:Malaria, Dengue, and West Nile Virus". Emergency Medicine Practice, 16:1-23.

3. Afolabi, O.J., Simon-Oke, I.A., Sorungbe, A.A., Alao, A.A. (2015): Prevalence of Malaria among Biological Science Students in Federal University of Technology Akure, Nigeria. Nature and Science, 13 (2): 6-12.

4. Behrens, R. H., Nadjm, B. (2012). "Malaria: An Update for Physicians". Infectious Disease Clinics of North America, 26 (2): 243-259.
5. Pasquetto, V., Guidotti, L. G., Kakimi, K., Tsuji, M., Chisari, F. V. (2000). Host-Virus Interactions during Malaria Infection in Hepatitis B Virus Transgenic Mice. Journal Experimental Medicine, 192: 529-536.

6. Fairley, T. L., Kilpatrick, C. W., Conn, J. E. (2012). Intragenomic Heterogeneity of Internal Transcribed Spacer Rdna in Neotropical Malaria Vector Anopheles aquasalis (Diptera: Culicidae). Journal Medicine Entomology, 42: 795-800.

7. Raphael, R. D., Strayer, S. Philadelphia [u.a.]: Wolters Kluwer/Lippincott Williams \& Wilkins. 2008: 638pp. ISBN 9780781795166.

8. Froebel, K., Howard, W., Schafer, J. R., Howie, F., Whitworth, J., Kaleebu, P., Brown, A.L., Riley, E. (2004). Activation by malaria antigens renders mononuclear cells susceptible to HIV infection and re-activates replication of endogenous HIV in cells from HIV-infected adults. Parasite Immunology, 26:213-217.

9. World Health Organization, UNAIDS, (2007). "2007 AIDS epidemic update" (PDF). p. 1

10. Garg, H., Mohl, J., Joshi, A. (2012). "HIV-1 Induced Bystander Apoptosis". Viruses, 4 (11): 3020-3043.

11. Kumar, V. (2012). Robbins Basic Pathology (9th ed.). p. 147. ISBN 9781455737871.

12. World Health Organization. (WHO) (2011). Roll Back Malaria Partnership: World Malaria Report (2011); World Health Organization; Geneva.?

13. Hay, S. I., Guerra, C. A., Gething, P. W., Patil, A. P., Tatem, A. J., Noor, A. M., Kabaria, C. W., Manh, B. H., Elyazar, I. R., Brooker, S., Smith, D. L., Moyeed, R. A., Snow R. W. (2007). A World Malaria Map: Plasmodium falciparum Endemicity in . PLoS Medical, 6(3): 112-114.

14. Denue, B. A., Gashau, W., Bello, H. S., Kida, I., Bakki, B., Ajayi, B. (2013). Relationship between some Hematological Abnormalities, Degree of Immunosuppresion and Viral Load in Treatment-naïve HIV Infected Patients Eastern Nigeria. East Mediterran Health Journal, 19(5): 362-368.

15. Orlov, M., Vaida, F., Finney, O.C. et al. (2012). Plasmodium falciparum enhances HIV replication in an experimental malaria challenge system. PLOS One, 7: e3900.

16. Sharif, A.A., Dabo, N.T., Getso, M.I., Yusuf, I., Muhd, I.Z., Ahmad, I.M. (2016). Liver Function of biomarkers in malaria and hepatitis B coinfection among patients with febrile illness in Kano metropolis. Int J Biol Med Res 7 (1); 5377 5380.

17. Barcus, M.J., Hien, T.T/, Laras, K. et al. (2002). Short report: Hepatitis B infection and Severe Plasmodium falciparum malaria in Vietnamese adults. American Journal of Tropical Medicine and Hygiene, 66(2): 140-142.

18. Olatunji, M.K., Sylviane, N.K. (2017). Hepatitis B virus and malaria coinfection causing significant changes in hematological and liver function indices in a cohort of subjects in Ilorin, Nigeria. International Journal of Infection, 5 (3): e81528. 